\title{
José Andújar Almansa, Los paisajes magnéticos (Ensayos sobre poesía), Granada, Colección Maillot Amarillo, Diputación, 2011, 291 pp.
}

José Andújar Almansa (almeriense nacido en 1963) es uno de los críticos españoles más prestigiosos de la actualidad. Su trayectoria viene jalonada por significativos libros y brillantes apariciones en los repertorios y compilaciones sobre poesía española contemporánea española más destacados de los últimos tres lustros. Ni qué decir tiene que la aparición de cualquier escrito suyo suele ser un acontecimiento anunciador que clarifica el panorama de las letras españoles, pone nombres y clasificaciones, establece criterios, sitúa y resitúa, valorando y colocando en su lugar oportuno a diferentes autores y voces, corrientes y estilos, y estableciendo, de este modo, una taxonomía o catalogación de la realidad poética y crítica, siempre escurridiza de las últimas hornadas. «Última» quiere decir últimas décadas, ya que no por referirnos a la segunda mitad del siglo XX está todo dicho, antes bien, está todo por hacer y por decir, una vez que vamos adquiriendo la consabida perspectiva histórica. En ese sentido hay miradas que son capaces de establecer esa perspectiva con más lucidez que otras, como la que aquí nos ocupa.

Andújar Almansa ha participado en los debates más calientes sobre las corrientes poéticas españolas de las últimas décadas en diferentes publicaciones periódicas o congresos, convirtiéndose sus opiniones en referente, y su sola mención en auctoritas. La razón de esta situación de Andújar Almansa en el panorama de la crítica se debe a varias razones, primero a su trabajo desinteresado, ya que cuando ha presentado alguna catalogación o propuesta no ha llevado detrás ninguna letra pequeña, ni proyecto para su propia editorial o antología (que no tiene), vaticinando por dónde irá la poesía española del futuro, sino que se ha dedicado a exponer las razones de por dónde va. José Andújar es profesor de Enseñanza Secundaria en Almería y, como tal, vive alejado del mundanal ruido de las corrientes y los cenáculos literarios. La segunda razón se debe a su claridad expositiva, que llama la atención por encima de cualquier otra cualidad, convirtiéndose en su aval más seguro: sus aportaciones didácticas razonadas y razonables, su rigor metodológico, su rigor y sensatez, su justa medida a la hora de calibrar cuáles son las propuestas más interesantes y cuáles no, qué suena a ganga y a fuego de artificio fugaz, qué posee más márgenes de estabilidad, duración, permanencia.

Ahora el crítico almeriense nos regala una nueva publicación que viene a poner orden en el siempre revuelto panorama de la poesía española contemporánea, desbrozando el terreno para las posteriores incursiones de otros críticos, que tendrán que contar con estos textos como punto de partida, debido, como hemos dicho, a su extraordinaria utilidad crítica y pedagógica. Los paisajes magnéticos (Ensayos sobre poesía) aparece en la prestigiosa Colección Maillot Amarillo, de la Diputación de Granada, y reúne doce textos casi todos publicados aquí y allá (alguno hay inédito) y ahora convenientemente revisados y retocados para esta edición. Cabe destacar de los textos, y todo hay que decirlo, que han sido publicados en las más prestigiosas revistas del hispanismo actual, tales como la histórica Ínsula. Revista de letras y ciencias y humanas (Madrid), o la Revista Hispánica Moderna (Nueva York); sin contar otras publicaciones periódicas más jóvenes pero ya consolidadas como Campo de Agramante. Revista de literatura (Jerez de la Frontera, Cádiz), El maquinista de la Generación y Litoral (ambas malagueñas), o Paraíso. Revista de poesía (Jaén); aparte de otros escritos aparecidos en volúmenes misceláneos u homenajes, prólogos a antologías, etc. Aunque también queda espacio para algún ensayo inédito como con el que se inicia el volumen, «Sin permiso de ser ángel» (pp. 17-37), sobre el Diario (1944-2000) del recientemente fallecido Carlos Edmundo de Ory. Continúa con «Tema del infractor y el héroe» (pp. 39-58), dedicado a José Manuel Caballero Bonald y dividido en dos partes, una sobre Descrédito del héroe (1977) y la otra sobre Manual de infractores (2005)... y así hasta diez más, pasando por artículos sobre Carlos Barral («El oficio de vivir, el oficio de poeta», pp. 59-73), Joan Margarit («Palabras contra el frío», pp. 75-83), Carlos Marzal («Los países al fin de la noche», pp. 85-95), Aurora Luque («Las grecias invitadas», pp. 97-109), Luis 
Muñoz («Correspondencias de poesía y vida», pp. 111-124), Javier Rodríguez Marcos («Las señas del viajero», pp. 125-132), y Luis García Montero («La lucidez y la quimera», pp. 183-244), amén de dos artículos sobre temas tan diversos como "Nocturno», alrededor de la noche y sus mitos modernos (pp. 135-156), y unas reflexiones sobre Vicente Aleixandre a propósito de la idea del paraíso, comparándola con Luis Cernuda o Rafael Alberti («El paraíso en ruinas», pp. 157-182). Broche final son unas consideraciones tituladas «Poesía última. Apuntes del natural» (pp. 245-283) donde Andújar Almansa da un repaso exhaustivo a las últimas tendencias y pone los puntos sobre las íes en los temas, conflictos y corrientes más destacadas, con una madurez extremadamente lúcida.

A su vez el libro está dividido en dos partes abarcadoras de todo este conjunto misceláneo de ensayos tituladas «Campos magnéticos» y «Paisajes», las cuales vienen a delimitar grosso modo el corte algo más «académico» de los textos, si bien con igual rigor y profundidad de los estudios, puesto que en los segundos se trata de artículos algo más extensos. La línea argumentativa que los une no puede ser otra que la contemporaneidad y la puesta en valor de esos textos, la indagación en aspectos antes no tratados por la crítica, la explicación atractiva de los ejes más sustanciales por los que discurre la poesía española actual. Todo un libro para los lectores más atentos sobre lo que se está cociendo no solo en las últimas hornadas sino también para aquellos que quieren descubrir y releer otra lectura atenta de aquellos aspectos que ponen luz sobre los temas que de verdad son candentes, están quemantes, resultan importantes.

Juan Carlos Abril 